See discussions, stats, and author profiles for this publication at: https://www.researchgate.net/publication/323695426

\title{
STRATEGI PENGEMBANGAN KAMPUNG BATU MALAKASARI SEBAGAI DAYA TARIK WISATA MINAT KHUSUS
}

Article $\cdot$ November 2017

CITATIONS

0

3 authors:

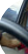

Erlangga Brahmanto

Bina Sarana Informatika

8 PUBLICATIONS 1 CITATION

SEE PROFILE

Faizal Hamzah

Bina Sarana Informatika

4 PUBLICATIONS O CITATIONS

SEE PROFILE

Some of the authors of this publication are also working on these related projects:

Pengembangan Destinasi Wisata Pada Tingkat Tapak Lahan View project

Project geowisata View project
READS

1,392

Hary Hermawan

Sekolah Tinggi Pariwisata AMPTA Yogyakarta

44 PUBLICATIONS 28 CITATIONS

SEE PROFILE 


\title{
STRATEGI PENGEMBANGAN KAMPUNG BATU MALAKASARI SEBAGAI DAYA TARIK WISATA MINAT KHUSUS
}

\author{
Erlangga Brahmanto \\ NIDN : 0511058204 \\ erlangga.egb@bsi.ac.id \\ Dosen AKPAR BSI Bandung
}

Hary Hermawan

haryhermawan8@gmail.com

Dosen STP ARS Internasional Bandung

\author{
Faizal Hamzah
}

Faizal.faz@bsi.ac.id

Dosen AKPAR BSI Bandung

\begin{abstract}
Special interest tourism is one of the forms of attraction development recommended in the Regional Tourism Development Master Plan (RIPDA) of Bandung Regency. Therefore, realizing the special interest attraction of interest in Kampung Batu Malakasari destination is the most appropriate strategy in the development of the next destination. This article discusses how the strategy in developing Kampung Batu Malakasari to become a special interest tourist attraction. using qualitative studies and SWOT analysis resulted in several recommendations related to the strategy of developing special interest interest in Kampung Batu Malakasari, are: (1) Packaging special interest attractiveness; (2) Presenting geotourism based education (geowisata); (3) Provide staff training as a natural and cultural interpreter; (5 Improve accessibility to increase tourist comfort; (6) Involving citizens in tourism management with the concept of community-based tourism management.
\end{abstract}

Keywords: Tourism attractions, special interest tourism, educational tourism, tourism

\section{PENDAHULUAN}

Sektor kepariwisataan telah tumbuh menjadi sektor unggulan dengan pertumbuhan tercepat di dunia dan menjadi lokomotif pertumbuhan ekonomi. Bahkan sektor pariwisataterbukti mampu memberi kontribusi sebesar 9,5\% pada Produk Domestik Bruto (PDB) global (Yahya 2015).

Pariwisata juga terbukti pro terhadap perkembangan ekonomi kerakyatan, melalui Community Based Tourism(CBT), pariwisata mampu menjadi pendorong kemajuan perekonomian rakyat di pedesaan, di antaranya: (1) Mampu meningkatkan penghasilan masyarakat; (2) Membuka peluang kerja; (3) Meningkatkan kesempatan berusaha; (4) Meningkatkan kepemilikan dan kontrol masyarakat lokal terhadap pengelolaan sumber daya desa; (5) Meningkatkan pendapatan pemerintah melalui retribusi wisata dan lain sebagainya (Hermawan, 2016).

Melalui pengembangan desa wisata, pariwisata juga terbukti mampu 
meningkatkan kesejahteraan sosial masyarakat lokal, meningkatkan kepedulian terhadap lingkungan, serta memotivasi masyarkat untuk lebih bangga terhadap identitas budayanya (Hermawan, 2016). Oleh karena itu, sangat tepat jika Pemerintah telah berkomitmen menempatkan kepariwisataan sebagai tulang punggung perekonomian negara, dengan menempatkan pariwisata sebagai prioritas pembangunan Nasional.

Pemerintah melalui Kementerian Pariwisata (Kemenpar) menetapkan enam target utama pembangunan pariwisata, diantara yang sangat strategik adalah target peningkatan indeks daya saing pariwisata dari peringkat 70 pada tahun 2014 menjadi 30 pada tahun 2019, sekaligus meningkatkan jumlah kunjungan wisatawan mancanegara (Yahya, 2015).

Kedua target pembangunan pariwisata diatas dapat dicapai dengan sinergi yang baik pada tingkatan hulu-hilir, antara pemerintah melalui Kemenpar dengan pengelola destinasi wisata di berbagai daerah dalam mengembangkan daya tarik wisata yang berkualitas.

Daya tarik wisata yang unggul dan berkualitas merupakanfaktor kunci yang menentukan motivasi wisatawan untuk berwisata, serta sebagai alasan fundamental yang menjadi pertimbangan mengapa seseorang memilih satu destinasi (Ritchie and Crouch, 2003). Daya tarik juga merupakan faktor utama yang menentukan kepuasan serta loyalitas wisatawan. Loyalitas wisatawan sendiri merupakan aspek yang menjamin keberlanjutan bisnis (Hermawan, 2017).

Indonesia sebagai Negara yang memiliki kekayaan alam melimpah sangat potensial untuk pengembangan destinasi wisata berbasis alam. Baik ekowisata, wisata alam binaan, maupun wisata minat khusus (Darsoprajitno, 2002). Salah satu daerah yang memiliki potensi strategik adalah Kabupaten Bandung, tepatnya di Desa Malakasari, Kecamatan Baleendah, Kabupaten Bandung, Jawa Barat.

Desa Malakasari memiliki kekayaan alam yang sangat beragam berupa keanekaragaman potensi geologi berupa hamparan gunung dan lembah menghasilkan lansekap alam yang indah. Kondisi geografis Desa Malakasari yang berada di dataran tinggi mampu menghasilkan udara sejuk, serta keberagaman flora dan fauna. Selain itu, posisi geografisnya yang dekat dengan Kota Jakarta sebagai salah satu gerbang utama kedatangan wisatawan merupakan prospek dan keuntungan tersendiri.

Dibalik potensi yang ada, faktanya Kabupaten Bandung belum memiliki daya tarik wisata berbasis alam yang unggul. Kurangnya sinergi dan integrasi hulu ke hilir, antara Pemerintah dan pelaku industri wisata menjadi akar masalah dari kurangnya kualitas dan daya saing daya tarik wisata. Contoh, Rencana Induk Pengembangan Pariwissata Daerah (RIPDA) Kabupaten Bandung, merekomendasikan pengembangan wisata berbasis alam diarahkan untuk : (1) Pendidikan ekowisata; (2) Pendidikan agrowisata; (3) Pendidikan geowisata; (4) Penyediaan pasar wisata sayur-mayur dan buah-buahan; (5) Penyediaan terminal pusat pemberangkatan tour; (6). Pengelolaan lingkungan yang berdasarkan kepada pemanfaatan alam sebagai konservasi, rekreasi, dan edukasi Akan tetapi, fakta dilapangan belum banyak pengelolaan destinasi berbasis alam pada tingkatan hilir di Kabupaten Bandung yang merepresentasikan RIPDA (Peraturan Daerah Kabupaten Bandung Nomor 6 Tahun 2006 Tentang Rencana Induk Pengembangan Pariwisata Daerah (RIPDA) Tahun 2006 sampai dengan tahun 2016). 
Berdasarkan latar belakang diatas, artikel ini mencoba menyajikan upaya pengembangan Kampung Batu Malakasari secara aktual, serta merumuskan strategi pengembangan Kampung Batu Malakasari sebagai daya tarik wisata minat khusus melalui kajian ilmiah kepariwisataan yang mendalam.

\section{LITERATUR REVIEW}

\section{Destinasi Wisata}

Destinasi adalah tempat yang dikunjungi dengan waktu yang signifikan selama perjalanan seseorang dibandingkan dengan tempat lain yang dilalui selama perjalanan (Pitana dan Putu, 2009). Berdasarkan sumber daya yang dimiliki, destinasi wisata dapat digolongkan menjadi : (1) Destinasi sumber daya alam seperti iklim, pantai, hutan; (2) Destinasi sumber daya budaya seperti tempat bersejarah, museum, teater, dan masyarakat lokal; (3) Destinasi sumber daya buatan manusia seperti fasilitas rekreasi atau taman hiburan; (4) Event seperti Pesta Kesenian Bali, Pesta Danau Toba, pasar malam dan sebagainya (Pitana dan Putu, 2009).

\section{Daya Tarik Wisata}

Daya tarik wisata dijelaskan dalam Undang-Undang Nomor 10 Tahun 2009 sebagai segala sesuatu yang memiliki keunikan, keindahan, dan nilai yang berwujud keanekaragaman kekayaan alam, budaya, dan hasil buatan manusia yang menjadi sasaran atau tujuan kunjungan wisata. Damanik dan Weber (2006) menekankan pentingnya keaslian dalam menentukan kualitas daya tarik wisata, baik dari segi originalitas, maupun otentisitasnya. Kualitas daya tarik merupakan faktor utama yang menentukan kepuasan dan loyalitas wisatawan dalam berwisata alam, sedangkan loyalitas dalam dimensi bisnis merupakan aspek yang menjamin keberlanjutan bisnis.
Maka kunci dari keberlanjutan destinasi wisata alam terletak pada sejauh mana kemampuan manajemen mengelola daya tarik wisatanya (Hermawan, 2017).

Ditinjau berdasarkan komposisi sumber dayanya, Kampung Batu Malaka sari memiliki daya tarik potensi alam, dan sedang dibangun beberapa fasilitas dan daya tarik buatan sebagai penunjang. Karena adanya campuran daya tarik wisata alam dan daya tarik buatan beserta fasilitas wisatanya, maka Kampung Malaka termasuk kategori wisata alam binaan, sesuai konsep yang diajukan Darsoprajitno (2002) dalam bukunya yang berjudul ekologi pariwisata.

\section{Daya Tarik Wisata Minat Khusus}

Daya tarik wisata terdiri dari tata alam, masyarakat, dan hasil binaan. Dari ketiganya, ada beberapa unsur yang dapat dikembangkan secara khusus, sehingga disebut daya tarik wisata minat khusus (Darsoprajitno, 2002). Pada prinsipnya, pariwisata minat khusus mempunyai kaitan dengan petualangan. Wisatawan secara fisik dapat menguras tenaga, serta ada unsur tantangan yang harus dilakukan, karena bentuk pariwisata ini banyak terdapat di daerah terpencil, seperti : kegiatan tracking, hiking, pendakian gunung, rafting di sungai, dan lainnya (Fandeli, 2000).

Ada beberapa kriteria menurut Fandeli dalam Sudana (2013), yang dapat dipergunakan sebagai pedoman dalam menetapkan suatu bentuk wisata minat khusus yakni : (1) Learning, pariwisata yang mendasar pada unsur belajar; (2) Rewarding, pariwisata yang memasukkan unsur pemberian penghargaan; (3) Enriching, pariwisata yang memasukkan peluang terjadinya pengkayaan pengetahuan antara wisatawan dengan masyarakat; Adventuring, pa riwisata yang dirancang dan dikemas sehingga terbentuk wisata petualangan. 


\section{Wisatawan}

Wisatawan secara sederhana dapat dimaknai sebagai orang yang melakukan kegiatan wisata. Fridgen (1990) mengembangkan tipologi wisatawan yang dibedakan menurut minat dan pola kunjungan wisatanya menjadi 2 jenis wisatawan, yaitu allocentric dan psychocentric. Allocentric merupakan tipe wisatawan yang lebih menyukai tempattempat yang belum banyak diketahui atau dijangkau orang lain. Dalam studi lebih lanjut, diketahui bahwa wisatawan berkarakter allocentric dan petualang cenderung lebih puas berwisata di daya tarik wisata berbasis alam yang masih memiliki keaslian, keindahan, keunikan, dan nilai berupa pengalaman berwisata (Hermawan, 2017).

Sedangkan yang dimaksud wisatawan berkarakter psychocentric adalah wisatawan yang hanya mau mengunjungi destinasi wisata yang sudah memiliki fasilitas penunjang yang langkap, standar sesuai yang ada di daerah asalnya. Wisatawan jenis ini lebih suka berwisata menggunakan jasa usaha perjalanan dengan program yang sudah pasti. Terakhir, ada kemungkinan juga wisatawan memiliki berkarakter diantara allocentric dan psychocentric, atau dapat disebut mid-centric.

\section{Perencanaan Strategik}

Perencanaan strategis muncul dan diminati berkaitan dengan semakin terbatasnya sumber daya internal organisasi serta banyaknya tantangan eksternal yang dipengaruhi kinerja dan peran organisasi (Baiquni, 2004). Perencanaan strategis merupakan pendekatan prinsip efektifitas dan efisiensi dalam menggali sumber daya (Hunger dan Wheelen, 2001). Manajemen strategis mengamati lingkungan eksternal untuk melihat kesempatan dan ancaman, serta mengamati lingkungan internal melihat kekuatan dan kelemahan. Faktor-faktor lingkungan itu disebut dengan SWOT yaitu : Strengths, Weaknesses, Opportunities, and Threats (Hunger and Wheelen, 2001).

\section{METODE PENELITIAN}

Pendekatan kualitatif dipilih untuk menggali data, menganalisis akar permasalahan, serta merumuskan bagaimana konsep pengembangan daya tarik wisata Kampung Batu Malakasari sebagai daya tarik wisata minat khusus. Pendekatan kualitatif dipilih karena mampu memperoleh gambaran diskriptif yang lebih luas terhadap fenomena yang diamatai (Moleong, 1995). Pendekatan kualitatif juga dipandang mampu menggali pemaknaan yang lebih mendalam terhadap fenomena-fenomena (Creswell, 1994). Fenomena yang dimaksud mengenai potensi daya tarik wisata Kampung Batu Malakasari.

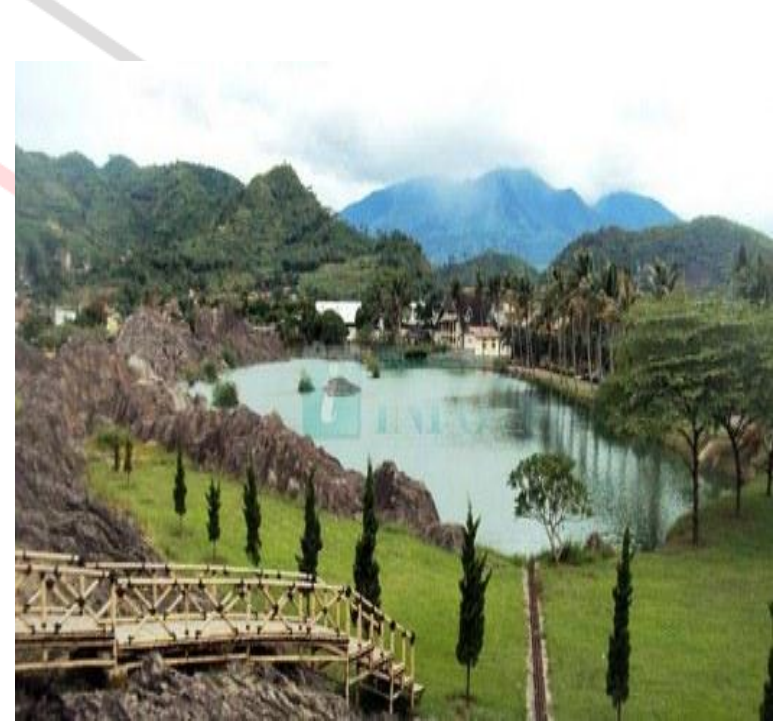

Gambar 1. Destinasi Kampung Batu Malakasari, sumber: kampungbatu.co.id

Pengumpulan data dilakukan dengan teknik observasi langsung serta dokumentasi terhadap kawasan guna memperoleh data primer non verbal, berupa gambaran potensi daya tarik alam Desa Malakasari (Sugiyono, 2004). Selain itu data juga diambil berupa hasil wawancara kepada narasumber. 
Narasumber yang dimaksud meliputi : (1) Pengelola Destinasi Wisata Kampung Batu Malakasari, dalam memperoleh gambaran pengelolaan daya tarik wisata aktual di Kampung Batu Malakasari; (2) Wisatawan, untuk memperoleh gambaran mengenai persepsi wisatawan terhadap daya tarik Kampung Batu Malakasari, serta mengetahui gambaran kebutuhan dan keinginan wisatawan terhadap daya tarik wisata.

Sebagai jaminan kevalidan data, dilakukan kroscek menggunakan 3 data dan 3 sumber data, biasa dikenal sebagai triangulasi data. Sedangkan analisis dilakukan dengan mengacu pada kaidahkaidah metodologi kualitatif secara umum seperti reduksi, penyajian data, verifikasi serta triangulasi data (Moleong, 1995).

Selain itu, analisis SWOT juga digunakan untuk melihat faktor-faktor yang menjadi kekuatan objek (strengs), kelemahan objek (weakness), peluang pengembangan (opportunities), serta kemungkinan faktorfaktor luar yang menjadi ancaman (treaths) agar diperoleh alternatif strategi serta rekomendasi positif dalam pengembangan daya tarik wisata Kampung Batu Malakasari selanjutnya (Rangkuti, 2011).

\section{HASIL PENELITIAN DAN PEMBAHASAN}

\section{Gambaran Umum Kampung Batu Malakasari}

Kampung Batu Malakasari, Baleendah yang terletak di Jalan Raya Banjaran (Rencong), Desa Malakasari, Kecamatan Baleendah, Kabupaten Bandung. Lokasi ini pada awalnya merupakan lokasi penambangan batu alam (adesit) yang dilakukan secara tradisional oleh masyarakat. Bentuk permukaan wilayah bekas tambang galian C pada umumnya tidak teratur dan sebagian besar dapat berupa morfologi terjal. Mengacu kepada perubahan tersebut perlu dilakukan upaya reklamasi dan rehabilitasi lahan, yang diharapkan menghasilkan nilai tambah bagi lingkungan serta menciptakan keadaan yang jauh lebih baik di bandingkan dengan keadaan sebelumnya (Anonim, 2017).

Reklamasi tidak berarti akan mengembalikan kondisi tersebut sama dengan kondisi awal, namun dapat juga berubah sesuai dengan penetapan tata guna lahan wilayah tersebut, seperti kemungkinan menjadi kawasan ekowisata. Pada tahun 2002 reklamasi lahan bekas tang batuan andesit di Desa Malakasari dimulai oleh manajemen Kampung Batu Malakasari. Keberadaan bekas galian sengaja dibiarkan sehingga mementuk danau yang mampu menampung puluhan ribu kubik air dengan bukit batu yang mengelilingi danau tersebut. Kemudian ditambah dengan wahana lain yang memiliki nilai edukatif untuk kegiatan wisata.

Selain memiliki daya tarik alam yang unik, kawasan ini juga memiliki fungsi ekologi yang tinggi bagi lingkungan hidup. Danau seluas $70 \%$ di kawasan ini merupakan sumber pengisian air bumi (akifer) yang berguana sebagai sumber air bagi lingkungan sekitar.

Keragaman tanaman yang ada di kawasan ini berfungsi sebagai filter udara bagi lingkungan di sekitarnya seperti : kelapa, palem, cengkeh, cemara, lengkeng, rambutan, mangga, nangka, sukun, petai, petai cina, jengkol, belimbing, sirsak, jambu biji merah, jambu jamaika, jambu air, juga terdapat tanaman langka seperti sawo durian, sawo walanda, bisbul atau apel beludru, dan lain-lain.

Adapun konsep yang disuguhkan oleh Kampung Batu Malakasari adalah Smart \& Fun Outbound. Destinasi wisata ini menyediakan berbagai macam wahana bahkan sudah dikemas dalam berbagai jenis 
paket wisata seperti paket wisata pelajar (wisata edukasi). Data hasil observasi inventori daya tarik wisata Kampung Batu Malakasari secara lebih lengkap disajikan pada tabel berikut.

Tabel 1. Jenis Wahana dan Aktifitas di Kampung Batu Malakasari

\begin{tabular}{|c|c|c|}
\hline No & Jenis wahana & $\begin{array}{c}\text { Aktifitas yang } \\
\text { dilakukan }\end{array}$ \\
\hline 1 & Wahana Danau & Berperahu, memancing \\
\hline 2 & $\begin{array}{l}\text { Wahana Bukit } \\
\text { Batu }\end{array}$ & Jelajah gunung batu \\
\hline 3 & $\begin{array}{l}\text { Wahana } \\
\text { Peternakan Sapi, } \\
\text { Domba, } \\
\text { Kambing, } \\
\text { Kelinci, dan } \\
\text { Penangkaran } \\
\text { Rusa Totol }\end{array}$ & $\begin{array}{l}\text { Ngangon meri } \\
\text { (menggembala itik), } \\
\text { memerah susu sapi, } \\
\text { memberi makan } \\
\text { kambing, menangkap } \\
\text { kelinci, membuat } \\
\text { kompos, membuat telur } \\
\text { asin, memberi makan } \\
\text { rusa. }\end{array}$ \\
\hline 4 & $\begin{array}{l}\text { Wahana } \\
\text { Persawahan }\end{array}$ & $\begin{array}{l}\text { Membajak sawah } \\
\text { dengan kerbau, } \\
\text { menanam padi, } \\
\text { merawat padi. }\end{array}$ \\
\hline 5 & $\begin{array}{l}\text { Wahana } \\
\text { Perikanan }\end{array}$ & $\begin{array}{l}\text { Menangkap ikan atau } \\
\text { belut, bola lumpur. }\end{array}$ \\
\hline 6 & $\begin{array}{l}\text { Wahana } \\
\text { Perkebunan }\end{array}$ & $\begin{array}{l}\text { Pengamatan proses } \\
\text { pembibitan, } \\
\text { mencangkul, menanam, } \\
\text { mencangkok, stek }\end{array}$ \\
\hline 7 & $\begin{array}{l}\text { Wahana Theater } \\
\text { Film } 4 \text { Dimensi }\end{array}$ & $\begin{array}{l}\text { Menonton film dengan } \\
\text { efek } 4 \text { dimensi }\end{array}$ \\
\hline 8 & $\begin{array}{l}\text { Gedung } \\
\text { Teatrikal (Bale } \\
\text { Seni Budaya) } \\
\end{array}$ & $\begin{array}{l}\text { Pengarahan peserta, } \\
\text { pengenalan kaulinan } \\
\text { sunda }\end{array}$ \\
\hline 9 & $\begin{array}{l}\text { Anjungan } \\
\text { Rumah Adat } \\
\text { Sunda }\end{array}$ & $\begin{array}{l}\text { Pengenalan budaya } \\
\text { sunda dan alat-alat } \\
\text { tradisional yang } \\
\text { digunakan masyarakat } \\
\text { sunda }\end{array}$ \\
\hline 10 & $\begin{array}{l}\text { Wahana } \\
\text { Outbound dan } \\
\text { Flying Fox }\end{array}$ & $\begin{array}{l}\text { Rumah pohon, Burma } \\
\text { bridge, loop bridge, } \\
\text { jaring laba-laba (cargo } \\
\text { net), panjat dinding, } \\
\text { kukuyaan, jembatan } \\
\text { goyang }\end{array}$ \\
\hline 11 & $\begin{array}{l}\text { Tektona } \\
\text { Waterpark }\end{array}$ & $\begin{array}{l}\text { Berenang, berseluncur, } \\
\text { bermain air }\end{array}$ \\
\hline
\end{tabular}

Berdasarkan gambar 1 dan tabel 1 diatas, terlihat bahwa daya tarik wisata di Kampung Batu Malakasari cukup memiliki keragaman, keindahan dan estetika, keunikan, serta nilai edukasi. Daya tarik wisata yang memiliki nilai edukasi yang dimaksud adalah wahana yang mampu menambah pengetahuan baru, melatih syaraf kognitif seperti : proses pembibitan, proses menanam padi dan sebagainya, selain itu wahana-wahana diatas juga mampu melatih keterampilan dan syaraf motorik, seperti : aktifitas dan daya tarik jelajah gunung, berperahu, memancing, membajak sawah dan lain sebagainya di wahana danau, bukit persawahan, peternakan dan lainya. Selain itu, wahana di Kampung Batu Malakasari juga mengajarkan wisatawan memiliki dan menghargai rasa keindahan, estetika dan seni. Diantara wahana aktifitas dan daya tarik tersebut adalah Anjungan Rumah Adat Sunda yang mengajarkan seni tari dan budaya sunda.

\section{Analisis SWOT Daya Tarik Wisata}

\section{Kampung Batu Malakasari}

Rangkuti (2011) menjelaskan analisis SWOT secara rinci sebagai aspek-aspek yang menjadi kekuatan (strength), kelemahan (weakness), peluang (opportunity) dan ancaman (threat).

Berdasarkan data diskriptif diperoleh dengan metode observasi/pengamatan, wawancara dan hasil dokumentasi, maka peneliti menentukan skor kinerja objek dengan cara penilaian (judgement value). Skala penilaian untuk faktor positif (kekuatan dan peluang) sebagai berikut : 1 untuk nilai sangan lemah, 2 untuk nilai lemah, 3 untuk nilai kuat dan 4 untuk nilai sangat kuat. Sedangkan untuk menilai faktor negatif (kelemahan dan ancaman) digunakan skala dengan pola sebagai berikut : 1 untuk nilai sangat kuat), 2 untuk nilai kuat, 3 untuk nilai lemah, dan 4 untuk nilai sangat lemah. 
Nilai bobot ditentukan tergantung seberapa penting faktor tersebut, menurut hasil kajian teori-teori kepariwisataan. Peringkat dari yang paling penting adalah daya tarik wisata, sarana wisata, aksebilitas diikuti sistem pengelolaan. Jumlah ke seluruhan nilai bobot maksimal adalah satu (1). Untuk mempermudah pemberian nilai skor dan bobot digunakan tebel internal faktor strategi (IFAS) dan ekternalnya faktor strategi (EFAS) sebagai berikut :

\section{Internal Faktor Strategy (IFAS)}

Hasil penelitian terhadap internal faktor strategy di Kampung Batu Malakasari telah dirangkum dalam tabel berikut :

\section{Tabel 2. Internal Faktor Strategi (IFAS)}

\begin{tabular}{|c|c|c|c|c|}
\hline No & Kekuatan (strength) & Skor & Bobot & Total \\
\hline 1 & $\begin{array}{l}\text { Destinasi wisata wisata Kampung Batu Malakasari memiliki beberapa } \\
\text { daya Tarik yang unik sebagai kawasan geowisata. }\end{array}$ & 4 & 0,04 & 0,16 \\
\hline 2 & $\begin{array}{l}\text { Kampung Batu Malakasari memiliki beberapa fungsi ekologi yang } \\
\text { mampu menjadi daya tarik wisata alam minat kshusus }\end{array}$ & 4 & 0,035 & 0,14 \\
\hline 3 & $\begin{array}{l}\text { Memiliki beberapa jenis wahana yang dapat disesuaikan dengan } \\
\text { lingkungan alami . }\end{array}$ & 4 & 0,035 & 0,14 \\
\hline 4 & $\begin{array}{l}\text { Destinasi wisata telah dibangun sesuai dengan kearifan lokal budaya } \\
\text { setempat, yaitu Budaya Sunda. }\end{array}$ & 4 & 035 & 0,14 \\
\hline 5 & $\begin{array}{l}\text { Destinasi wisata Kampung Batu memiliki sebuah Tektona Waterpark } \\
\text { yang mempunyai fasilitas kolam arus dan kolam ombak satu-satunya di } \\
\text { Kab.Bandung }\end{array}$ & 4 &, 035 & 0,14 \\
\hline 6 & $\begin{array}{l}\text { Malaksari sudah memiliki sarana dan prasarana } \\
\text { cukup memadai. }\end{array}$ & 3 & 0,035 & 0,105 \\
\hline 7 & $\begin{array}{l}\text { Kampung Batu Malaksari menyediakan beberapa jenis wahana sebagai } \\
\text { sarana laboratorium alam seperti : wahana danau dan bukit batu, wahana } \\
\text { perikanan, wahana peternakan, wahana perkebunan, dan lain-lainnya. }\end{array}$ & 4 & 0,035 & 0,14 \\
\hline No & Kelemahan (weakness) & Skc & Bobot & Total \\
\hline 1 & $\begin{array}{l}\text { Pelayanan yang belum optimal menjadi satu faktor alasan dari kepuasan } \\
\text { tamu }\end{array}$ & 2 & 0,07 & 0,14 \\
\hline 2 & staff dalam memandu dan memberi interprestasi & 2 & 0,09 & 0,18 \\
\hline 3 & $\begin{array}{l}\text { Banyaknya fasilitas terbangun kurang diminati (tidak terpakai oleh } \\
\text { pengunjung) }\end{array}$ & 3 & 0,09 & 0,27 \\
\hline \multicolumn{2}{|c|}{ Total } & & 0,5 & 1,555 \\
\hline
\end{tabular}

Internal Faktor Strategy (IFAS) Kampung Batu Malakasari merupakan faktor-faktor daya tarik berupa kekuatan dan kelemahan yang ada dalam lingkup kendali dan kekuasaan manajemen atau pengelola, dalam marketing sering dikenal sebagai atribusi kontrol (Ali Hasan 2015). Jadi IFAS merupakan faktor, atau sumber daya yang sebenarnya dapat dikontrol oleh pengelola untuk dapat ditingkatkan maupun dikurangi untuk menyesuaikan berbagai tantangan dan gejolak lingkungan pariwisata yang ada.

\section{Eksternal Faktor Strategi (EFAS)}

Eksternal Faktor Strategi (EFAS) di Kampung Batu Malakasari telah dirangkum dalam tabel berikut : 
Tabel 3. Eksternal Faktor Strategi (IFAS)

\begin{tabular}{cllll}
\hline No & Peluang (opportunity) & Skor & Bobot & Total \\
\hline 1 & $\begin{array}{l}\text { Banyaknya anak sekolah di Kabupaten Bandung yang } \\
\text { merupakan segmen utama wisata edukasi }\end{array}$ & 4 & 0,11 & 0,44 \\
\hline 2 & $\begin{array}{l}\text { Konsep engembangan destinasi dengan tema minat khusus } \\
\text { sejalan dengan RIPDA }\end{array}$ & 3 & 0,07 & 0,21 \\
\hline 3 & $\begin{array}{l}\text { Kemungkinan pengembangan konsep geowisata untuk } \\
\text { memasarakan produk Kampung Batu Malakasari }\end{array}$ & 3 & 0,07 & 0,21 \\
\hline No & Ancaman (threat) & Skor & Bobot & Total \\
\hline 1 & $\begin{array}{l}\text { Kondisi perekonomian masyarakat yang masih sangat } \\
\text { bergantung pada ketersediaan sumber daya alam di dalam } \\
\text { kawasan, sehingga rawan pengambilan aset wisata untuk } \\
\text { pemenuhan hidup masyarakat }\end{array}$ & 3 & 0,013 & 0,039 \\
\hline 2 & $\begin{array}{l}\text { Bila terjadi musim hujan akses jalan menuju kawasan terhambat } \\
\text { dikarenakan terjadi banjir tahunan. }\end{array}$ & 4 & 0,012 & 0,048 \\
\hline Total & & & $\mathbf{0 , 5}$ & $\mathbf{0 , 9 4 7}$ \\
\hline
\end{tabular}

Eksternal faktor strategy Kampung Batu Malakasari merupakan faktor-faktor diluar kendali atau kekuasaan manajemen (pengelola). Jadi EFAS merupakan faktorfaktor lingkungan luar tidak dapat di kendalikan. Akan tetapi, EFAS dapat dihadapi dengan merekayasa atau mengadaptasikan Internal Faktor Strategy (IFAS), yang dimiliki perusahaan.

\section{Alternatif Strategy}

Dari kedua bagan diatas diketahui bahwa nilai internal faktor strategi sebesar 1,555 atau dibulatkan satu digit menjadi 2, yang bermakna lemah. Dalam hal ini maka daya tarik wisata Kampung Batu Malakasari masih butuh banyak perbaikan. Sedangkan nilai ekternalnya faktor strategi adalah 0,947 atau dibulatkan satu digit menjadi 1sangat lemah. Dalam hal ini bermakna bahwa peluang sedikit sedangkan maupun ancaman tinggi. Oleh karena itu, pengembangan Kampung Batu Malakasari perlu dilakukan secara hati-hati. Untuk merumuskan strategi lebih lanjut digunakan diagram SWOT seperti dalam gambar 2: Karena nilai IFAS sebesar 2 (lemah), sedangkan nilai EFAS 1 (sangat lemah), maka dengan alat bantu diagram diatas dipilihlah strategi untuk memperbaiki kelemahan untuk menghindari ancaman atau Weaknese to Threat (WO). Implementasi strategy memperbaiki kelemahan untuk menghindari ancaman atau Weaknese to Threat (WO) yang dapat diterapkan sebagai berikut : (1) Mengemas daya tarik wisata dengan lebih menonjolkan keunikan destinasi untuk kegiatan wisata minat khusus; (2) Menghadirkan wisata edukatif berbasis geologi/ geowisata dengan mengkaji fenomena alam geologi dan ekologi untuk menggali keunikan karakteristik alam Kampung Batu Malakasari; (3) Melakukan pelatihan staf sebagai pemandu dan intepreter alam dan budaya agar mampu menyuguhkan daya tarik yang lebih bernilai bagi wisatawan; (4) Mengkaji kembali penyediaan fasilitas dibanding segmen dan motif wisatawan yang datang; (5) Memperbaiki aksebilitas untuk menujang kenyamanan wisatawan, serta terhindar dari banjir musiman; (6) Melibatkan warga dalam pengelolaan wisata dengan model kelola pariwisata berbasis masyarakat Community Based Tourism (CBT), agar masyarakat ikut merasa memiliki, serta memiliki kepedulian terhadap keberlanjutan alam dan destinasi.

\section{Mengemas Daya Tarik Minat Khusus}

Dalam mewujudkan konsep pengembangan Kampung Batu Malakasari 
diperlukan pengemasan daya tarik wisata dengan lebih menonjolkan sisi keunikan destinasi untuk kegiatan wisata minat khusus menjadi rekomendasi paling utama, mengingat kunci dari keberlanjutan destinasi wisata alam terletak pada sejauh mana kemampuan manajemen mengelola daya tarik wisatanya (Hermawan, 2017).

Pengelolaan daya tarik wisata minat khusus menuntut adanya beberapa prinsip yang harus diwujudkan diantaranya (1) Learning, pariwisata yang mendasar pada unsur belajar; (2) Rewarding, pariwisata yang memasukkan unsur pemberian penghargaan; (3) Enriching, pariwisata yang memasukkan peluang terjadinya pengkayaan pengetahuan antara wisatawan dengan masyarakat; (4) Adventuring, pariwisata yang dirancang dan dikemas sehingga terbentuk wisata petualangan.

Berdasarkan hasil observasi dan inventori, Kampung Batu Malakasari dipandang sudah memiliki sumber daya alam dan wahana yang sudah cukup memadahi untuk mewujudkan unsur learning dan enriching atau belajar dan pengkayaan pengetahuan, dalam daya tarik wisata minat khusus. Kampung Batu Malakasari memiliki wahana dan aktifitas wisata yang mampu melatih syaraf kognitif dan menambah pengetahuan seperti : proses pembibitan, proses menanam padi dan sebagainya, selain itu wahana dan aktifitas yang ada juga mampu melatih keterampilan dan syaraf motorik, seperti : aktifitas dan daya tarik jelajah gunung, berperahu, memancing, membajak sawah dan lain sebagainya di wahana danau, bukit persawahan, peternakan dan lainya.Selain itu, wahana di Kampung Batu Malakasari juga mengajarkan wisatawan memiliki dan menghargai rasa keindahan, estetika dan seni. Diantara wahana aktifitas dan daya tarik tersebut adalah Anjungan Rumah Adat Sunda yang mengajarkan seni tari dan budaya sunda. Hanya saja mungkin diperlukan penyampaian yang lebih informatif dari para staf pemandu kepada wisatawan.

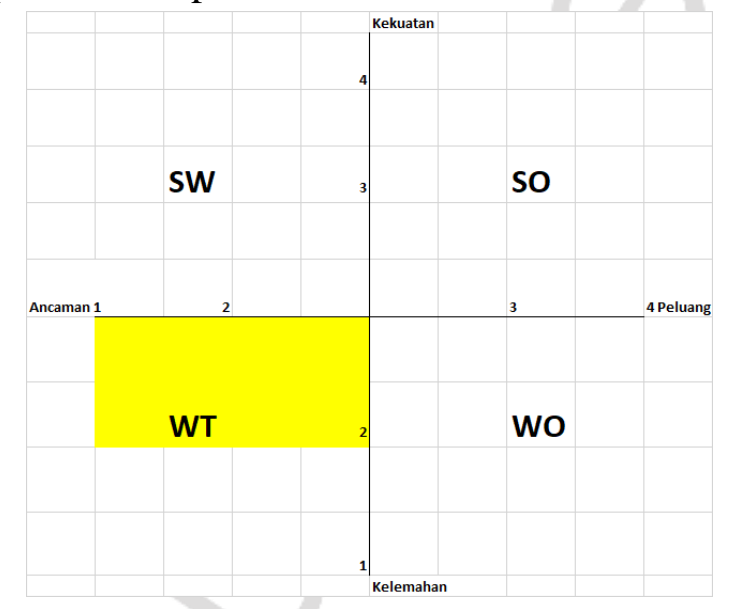

Gambar 2 Diagram SWOT (Adaptasi dari Rangkuti, 2011)

Rewarding atau penghargaan juga merupakan prinsip yang perlu diwujudkan dalam pengemasan daya tarik wisata minat khusus. Pengenalan budaya sunda melalui wahana Anjungan Rumah Adat Sunda dengan aktifitas belajar seni tari dan budaya sunda patut untuk lebih dikembangkan untuk menambah keunikan serta nilai jual (value of selling) destinasi wisata. Dengan aktifitas belajar seni tari dan budaya menjadikan wisatawan semakin aware dan menghargai terhadap budaya dan adat sunda. Pada akhirnya tujuan untuk pelestarian nilai seni dan budaya lokal akan tercapai melalui wisata minat khusus.

Rekomendasi terakhir dalam mengemas daya tarik wisata minat khusus adalah mewujudkan unsur adventure atau petualangan. Kampung Batu Malakasari memiliki daya tarik petualangan yaitu jelajah gunung batu. Walaupun rute yang dilewati wisatawan sangat pendek, dengan penamba-han nilai edukasi tentang lingkungan alam, melalui ilmu geologi dan ekologi akan menghasilkan wisata petualangan ringan yang bernilai edukasi. 
Menghadirkan Wisata Edukatif Berbasis

\section{Geologi (Geowisata)}

Wisata minat khusus berbasis geologi atau sering dikenal dengan geowisata sangat tepat untuk disajikan di Kampung Batu Malakasari mengingat kawasan ini memiliki karakteristik geologi khusus berupa gunung batu, serta sebagian lokasi ini pada awalnya adalah area penambangan batu alam (adesit) secara tradisional oleh masyarakat. Akan tetapi, dalam pengembangan geowisata sebelumnya perlu dilakukan kajian terlebih dahulu secara khusus dan mendalam mengenai keunikan geologi beserta fungsi ekologisnya. Mengingat bahwa daya tarik wisata yang dijadikan sebagai geowisata harus berupa bentukkan hasil proses geologi. Hasil proses geologi dalam hal ini berarti alamiah, bukan artifisial atau buatan manusia.

Wisata geologi atau geowisata dapat dijadikan media bagi sosialisasi ilmu pengetahuan alam, pendidikan lingkungan dan pelestarian alam dan pada akhirnya diharapkan akan terwujud pembangunan pariwisata yang berkelanjutan berbasis kearifan lokal.

\section{Memberikan Pelatihan Staf sebagai Intepreter Alam dan Budaya}

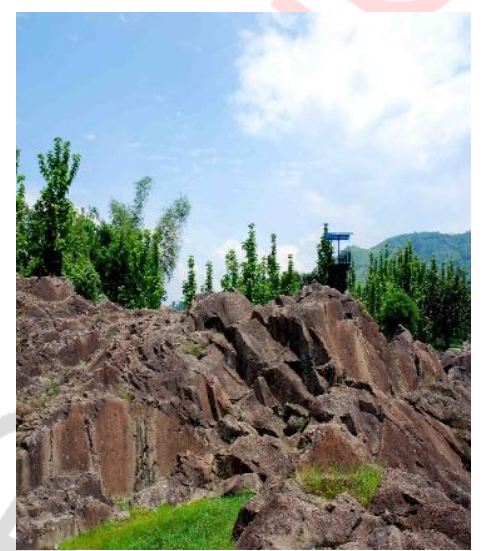

Gambar 3. Potensi geologi Kampung Batu Malakasari sumber: kampungbatu.co.id
Menindaklanjuti rekomendasi sebelumnya bahwa pengembangan daya tarik minat khusus berbasis geologi sebaiknya dilengkapi dengan informasi tentang sejarah terbentuknya bentukkan geologi tersebut agar wisatawan dapat paham proses proses alam yang terjadi. Dengan adanya informasi tersebut diharapkan wiatawan dan masyarakat akan sadar dan tidak berupaya merusak keindahan lingkungan di sekitar objek geowisata. Oleh karena, itu untuk menghadirkan interpreter yang terbaik dibutuhkan pelatihan khusus terhadap para staf pemandu wisata. Seorang interpreter dituntut untuk mampu menjelaskan secara benar dan ilmiah mengenai proses terbentuknya alam kepada wisatawan (Dirgantara, 2012)

Selain interpreter alam, interpreter budaya juga sangat dibutuhkan. Mengingat Kampung Batu Malakasari memiliki beberapa daya tarik wisata berbasis budaya, misalnya Anjungan Rumah Adat Sunda yang mengajarkan seni tari dan budaya sunda. Interpreter budaya setidaknya mampu menjelaskan secara kronologis maupun historis terbentuknya suatu budaya beserta nilai-nilai filosofi dan estetika didalamnya. Kinerja interpreter dalam wisata minat khusus sangat penting guna mewujudkan pelayanan prima kepada wisatawan.

\section{Mengkaji Kembali Penyediaan Fasilitas}

Berdasarkan hasil penelitian diketahui bahwa mayoritas sarana wisata kurang menarik bagi wisatawan. Dalam teori pemasaran Kotler (2002), bauran produk hendaknya dibuat cocok dengan kebutuhan dan keinginan pelanggan atau focus customer oriented, dalam konteks pariwisata adalah kebutuhan dan keinginan wisatawan.

Fasilitas dalam penelitian terdahulu terbukti tidak begitu signifikan dalam mempengaruhi kepuasan bagi wisatawan yang memiliki karakteristik petualang atau 
drifter, bahkan fasilitas wisata tidak ada hubunganya sama sekali dengan loyalitas wisatawan (Hermawan, 2017). Oleh karena itu mengkaji kembali segmen wisata mana yang akan dilayani sangat perlu untuk pengembangan dan evaluasi penyediaan fasilitas wisata selanjutnya.

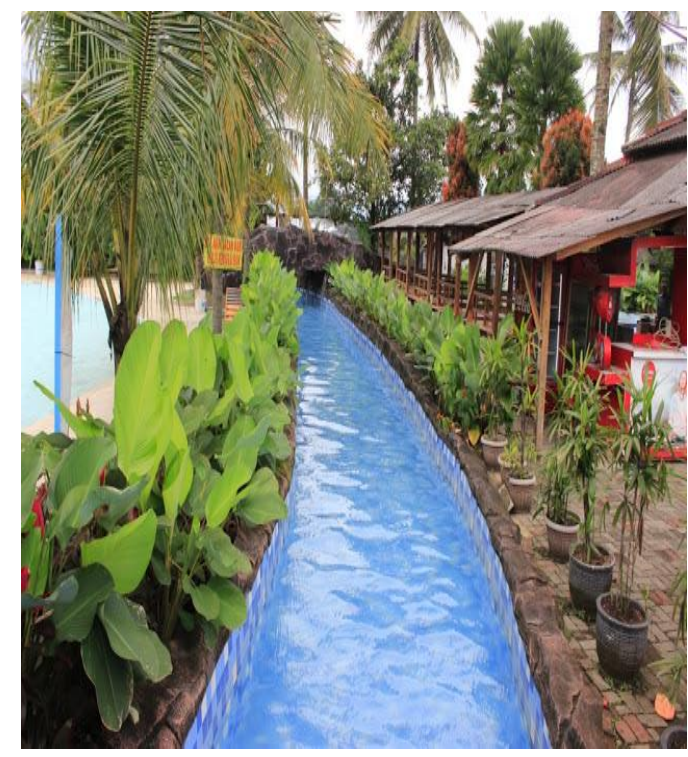

Gambar 4. Fasilitas wisata di destinasi sumber:notetraveling.net

Penelitian lebih lanjut diperlukan untuk mengetahui karakteristik wisatawan, apakah bertipe allocentric atau pshycocentric. Karena wisatawan allocentric cenderung akan mengabaikan fasilitas wisata, mereka lebih membutuhkan ketersediaan atraksi dan wahana yang menantang jiwa petualangnya.

Memperbaiki Aksebilitas untuk Menujang Kenyamanan Wisatawan

Aksebilitas merupakan salah satu unsur pariwisata yang sangat berperan dalam membentuk kualitas produk wisata keseluruhan. Menurut penuturan pengelola, aksebilitas wisata di Kampung Batu Malakasari sangat terkendala pada musim hujan. Oleh karena itu, jalan menuju destinasi perlu untuk diperbaiki dengan rekayasa enginering untuk menambah kenyamanan dan keamanan wisatawan.
Efektifitas, efisiensi, serta ektensifitas daya jangkau merupakan faktor yang perlu dipertimbangkan dalam pengembangan aksebilitas wisata (www.indonesiacultureandtourism.com).

\section{Melibatkan Warga dalam Pengelolaan Wisata Berbasis Masyarakat}

Dinamika pengelolaan Kampung Batu Malakasari berjalan bukan tanpa masalah. Menurut narasumber, pengelolaan Kampung Batu Malakasari terancam oleh oknum masyarakat yang mengambil beberapa sumber daya alam dilokasi, yang merupakan aset bagi daya tarik wisata. Salah satu solusi untuk menangani masalah ini adalah merumuskan dan mewujudkan pariwisata berbasis masyarakat. Prinsip-prinsip Cотmunity Based Tourism (CBT), yaitu pariwisata yang kepemilikan adalah komunitas lokal (Edi Darmawi, 2010; Hermantoro, 2011; Simanungkalit, dkk, 2015). Dengan melibatkan peran aktif masyarakat dalam pengelolaan, diharapkan masyarakat memiliki rasa kepedulian untuk merawat destinasi wisata Kampung Batu Malakasari beserta lingkungan alam sekitarnya.

\section{KESIMPULAN DAN REKOMENDASI}

Daya tarik wisata yang unggul dan berkualitas merupakan faktor kunci yang menentukan motivasi wisatawan untuk berwisata, serta sebagai alasan fundamental yang menjadi pertimbangan mengapa seseorang memilih satu destinasi. Daya tarik juga sangat menentukan kepuasan dan loyalitas wisatawan yang nantinya akan berdampak secara ekonomi terhadap keberlanjutan destinasi wisata.

Daya tarik wisata minat khusus merupakan salah satu bentuk pengembangan daya tarik yang direkomendasikan dalam Rencana Induk Pengembangan Wisata Daerah Kabupaten Bandung. Oleh karena itu, mewujudkan daya tarik wisata minat khusus 
di Kampung Batu Malakasari merupakan salah satu strategi yang paling tepat dalam pengembangan destinassi selanjutnya.

Penelitian ini merupakan kajian kualitatif dan analisis SWOT Destinasi Wisata Kampung Batu Malakasari, oleh karena itu hasil penelitian ini tidak dapat digunakan sebagai dasar generalisasi teoritis maupun strategi pengembangan destinasi wisata minat khusus lainnya. Dengan keterbatasan tersebut maka sejumlah rekomendasi pengembangan untuk mewujudkan daya tarik minat khusus di Kampung Batu Malakasari adalah sebagai berikut : (1) Mengemas daya tarik Kampung Malakasari sebagai daya tarik minat khusus berbasis alam dan budaya, dengan menonjolkan sisi keindahan, keunikan, serta keaslianya; (2) Menghadirkan wisata edukatif berbasis geologi (geowisata); (3) Memberikan pelatihan staf sebagai intepreter alam dan budaya yang profesional; (5) Memperbaiki aksebilitas untuk menujang kenyamanan wisatawan; (6) Melibatkan warga dalam pengelolaan wisata dengan model kelola pariwisata berbasis masyarakatagar masyarakat memiliki rasa dan kepedulian untuk merawat destinasi wisata Kampung Batu Malakasari beserta lingkungan alam sekitarnya; (7) Evaluasi kembali penyediaan fasilitas wisata.

\section{DAFTAR PUSTAKA}

Ali Hasan, 2015. Tourism Marketing. Yogyakarta: Center for Academic Publishing Service.

Anonim. 2006. Peraturan Daerah Kabupaten Bandung Nomor 6 Tahun 2006 tentang Rencana Induk Pengembangan Pariwisata Daerah (RIPDA) Tahun 2006 sampai dengan Tahun 2016. Indonesia. Tersedia (jdih.bandungkab.go.id, diakses 26 September 2017).
Anonim. 2009. Undang-Undang Nomor 10

Tahun 2009 Tentang Kepariwisataan. Indonesia.

Anonim. 2017. Ekowisata Kampung Batu Malakasari. Tersedia (kampungbatu.co.id, diakses 25 Oktober 2017).

Baiquni, M. 2004. Manajemen Strategis. Buku Ajar Pusat Studi Kajian Pariwisata Sekolah Pascasarjana Universitas Gajah Mada

Creswell, John W. 1994. Research DesignQualitative, Quantitative, and Mixed Method. London: SAGE Publications. Damanik, J. dan Weber. H. F. 2006. Perencanaan Ekowisata dari Teori ke Aplikasi. Diterbitkan atas Kerjasama Pusat Studi Pariwisata (PUSPAR) Universitas Gadjah Mada dan Penerbit Andi."

Darsoprajitno, Soewarno. 2002. Ekologi Pariwisata. Bandung: Penerbit Angkasa.

Dirgantara, Ahmad Rimba. 2012. Peran Interpreter dalam Kegiatan

Geowisata: Studi Kasus Gunung Tangkuban Perahu. Tersedia di https://scholar.google.co.id/scholar?q $=\% 22 \mathrm{Ahmad}+$ Rimba+

Dirgantara\%22\&hl, diakses 15 November 2017.

Edi Darmawi. 2010. Pengembangan Kepariwisataan Berbasis Masyarakat di Kota Bengkulu. Bengkulu: Fakultas Ilmu Sosial dan Ilmu Politik UMB Bengkulu.

Fandeli, Chafid. 2000. Pengusahaan Ekowisata. Diterbitkan atas kerjasama Fakultas Kehutanan UGM dengan Pustaka Pelajar dan Unit Konservasi Sumberdaya Alam DIY.

Fridgen, Joseph D. 1990. Dimensions of Tourism. Educational Institute of the American Hotel \& Motel Association. 
Hermantoro, Henky. 2014. Creative-Based

Tourism: Dari Wisata Rekreatif menuju Wisata Kreatif. LAP LAMBERT Academic Publishing.

Hermawan, Hary. 2016. Dampak Pengembangan Desa Wisata Nglanggeran terhadap Ekonomi Masyarakat Lokal. Jurnal Pariwisata, Vol 3, No 1, pp 105-117. . 2016. Dampak Pengembangan Desa Wisata Nglanggeran terhadap Sosial Budaya Masyarakat Lokal. pp. 42635. Dalam Seminar Nasional Ilmu Pengetahuan dan Teknologi Komputer Nusa Mandiri Pertama Tahun 2016, Vol 1, pp 426-435. . 2017. Pengaruh Daya Tarik Wisata, Keselamatan dan Sarana Wisata terhadap Kepuasan serta Dampaknya terhadap Loyalitas Wisatawan : Studi Community Based Tourism di Gunung Api Purba Nglanggeran. Wahana Informasi Pariwisata: Media Wisata, Vol 15, No1, pp 562577.

2017. Pengembangan Destinasi Wisata pada Tingkat Tapak Lahan dengan Pendekatan Analisis SWOT. Jurnal Pariwisata, Vol 4, No 2, pp 64-74.

Hunger, J. D. dan T. L. Wheelen. 2001. Strategic Management. Fifth Editions.

Kotler, Philip. 2002. Manajemen Pemasaran, Terjemahan Hendra Teguh, Edisi Millenium, Cetakan Pertama. Jakarta: Prenhalindo.

Moleong, Lexy. 1995. Metode Penelitian. Bandung: Remaja Rosda Karya.

Pitana, I. Gede dan G. Putu. 2009. Sosiologi Pariwisata. Yogyakarta: Andi.

Rangkuti, Freddy. 2011. SWOT: Balanced Scorecard. Jakarta: Gramedia Pustaka
Utama.

Ritchie, J. R.Brent dan Geoffrey Ian Crouch. 2003. The Competitive Destination: A Sustainable Tourism Perspective. Cabi.

Sudana, I. Putu. 2013. Strategi Pengembangan Desa Wisata Ekologis di Desa Belimbing, Kecamatan Pupuan Kabupaten Tabanan. Analisis Pariwisata, Vol 13, No 1, pp 11-31.

Sugiyono. 2004. Metode Penelitian Kombinasi. Bandung: CV Alfabeta.

Victoria br. Simanungkalit, Destry Anna Sari, Frans Teguh, Hari Ristanto, Ika K, Leonardo Sambodo, Samsul Widodo, Masyhud, Sri Wahyuni, Henky Hermantoro, Henky Hermantoro, Dian Vitriani. 2015. Buku Panduan Pengembangan Desa Wisata Hijau. Jakarta: Asisten Deputi Urusan Ketenagalistrikan dan Aneka Usaha Kementerian Koperasi dan UKM Republik Indonesia

Yahya, Arief. 2015. Sambutan Menteri Pariwisata R.I. Pada Peringatan World Tourism Day dan Hari Kepariwisataan Nasional. Tersedia (kemenpar.go.id, diakses 26 September 2017. 